\title{
Traduire
}

Revue française de la traduction

$229 \mid 2013$

L'environnement, une spécialisation durable?

\section{La traducción entre lenguas en contacto : catalán y español, Cristina García de Toro}

David Ar Rouz

\section{OpenEdition}

Journals

Édition électronique

URL : http://journals.openedition.org/traduire/600

DOI : $10.4000 /$ traduire.600

ISSN : 2272-9992

Éditeur

Société française des traducteurs

Édition imprimée

Date de publication : 15 décembre 2013

Pagination : $98-99$

ISSN : 0395-773X

Référence électronique

David Ar Rouz, "La traducción entre lenguas en contacto : catalán y español, Cristina García de Toro »,

Traduire [En ligne], 229 | 2013, mis en ligne le 15 décembre 2013, consulté le 25 septembre 2020. URL

http://journals.openedition.org/traduire/600 ; DOI : https://doi.org/10.4000/traduire.600

Ce document a été généré automatiquement le 25 septembre 2020. 
La traducción entre lenguas en contacto : catalán y español, Cristina García de Toro

David Ar Rouz

\section{RÉFÉRENCE}

La traducción entre lenguas en contacto : catalán y español, Cristina García de Toro, Peter Lang, Berlin, 2009, 182 pages. 
1 Dès l'introduction de l'ouvrage, on est frappé par la clarté du propos et de l'objectif: présenter un panorama des possibilités de recherche sur les langues en contact d'un $\mathrm{p}$ oint de vue traductologique, et ce à partir de la description de certaines pratiques de traduction entre l'espagnol et le catalan. La structure adoptée est parfaitement logique, allant du contexte théorique et géographique à des études de corpus en passant par les contextes particuliers de la paire de langues étudiée.

2 La première partie, entièrement inédite, passe d'abord en revue les principaux écrits de la sociolinguistique pour conclure que la dénomination de «traduction entre communautés aux

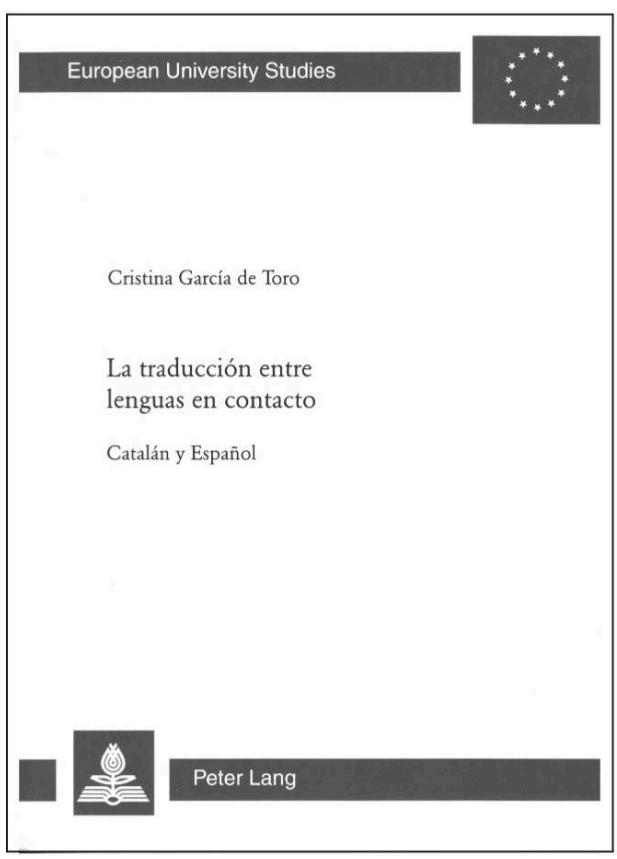
langues en contact » est préférable à celle de «traduction entre communautés de parole bilingues» (26). Dans le second chapitre, l'auteur reprend la suggestion de Miquel Siguan dans La Europa de las lenguas (1996) pour classer les États selon leur gestion du multilinguisme et situer alors l'Espagne dans la solution intermédiaire de l'«autonomie linguistique ». Elle fournit ensuite plus de détails sur les régions bilingues de cet État et en particulier celles de langue catalane, terminant sur les autres États où le catalan est également présent. Enfin, Cristina García de Toro s'efforce de déterminer la dénomination la plus juste pour son objet d'étude d'un point de vue traductologique : «traduction entre langues A » apparaît alors moins chargé idéologiquement et axiologiquement que «traduction entre langues maternelles ».

3 La deuxième partie s'attache à caractériser la traduction entre le catalan et l'espagnol qui se distingue surtout par la proximité formelle des deux langues, mais aussi par l'inégale répartition des demandes de traductions dans un sens ou dans l'autre suivant le domaine considéré : dans l'audiovisuel, on traduit ainsi davantage vers l'espagnol, alors que c'est l'inverse dans les autres domaines. L'enseignement de la traduction entre ces deux langues ne distingue d'ailleurs pas les groupes selon la langue maternelle des étudiants, ce qu'explique le cinquième chapitre traitant justement de cette question du sens de traduction. En effet, les langues en contact interrogent fortement le principe selon lequel on doit traduire vers sa langue maternelle puisque le marché exige souvent des professionnels concernés qu'ils traduisent dans les deux sens. L'auteur estime dans le sixième chapitre, consacré aux perspectives professionnelles et scientifiques, que la traduction étudiée a gagné en visibilité, tout en restant « loin de ce que l'on pourrait considérer comme une situation de normalité » (69).

4 Dans la troisième partie, on découvre le chemin parcouru dans le domaine de la traduction administrative, surtout de l'espagnol au catalan, depuis les débuts de la démocratie espagnole actuelle. Si les gouvernements et les parlements régionaux se sont attelés à la tâche avec opiniâtreté, pour la «normalisation linguistique » et tout en 
visant la modernisation du langage administratif, le domaine de la Justice, lui, reste à la traîne du fait de sa dépendance à l'échelon étatique. Le chapitre huit propose une classification plus complète que celles que l'on trouvait jusque-là des documents administratifs et se veut utile aux traducteurs en leur permettant par exemple l'utilisation de textes parallèles ou de modèles.

5 C'est la traduction littéraire - l'autre domaine où le catalan a pris une place conséquente - qui fait l'objet de la dernière partie. Le chapitre neuf, tiré de la thèse de l'auteur, étudie la traduction de trois œuvres du catalan à l'espagnol et constate un équilibre entre les stratégies d'acclimatation et d'étrangéisation. Le chapitre suivant est le moins directement lié à la question des langues en contact puisqu'il démontre surtout que, comme en traduction audiovisuelle, les marques d'oralité dans la littérature ont tendance à être standardisées, même si une grande partie l'est dès le stade de l'écriture. Le chapitre consacré à la phraséologie montre le rôle perturbateur que peut jouer la proximité des langues dans la perception de ces unités si particulières pour le traducteur (intéressantes par conséquent pour l'enseignement), tandis que le dernier chapitre, également fondé sur une expérience menée avec des étudiants, fait office de conclusion en reprenant, exemples à l'appui, plusieurs aspects évoqués auparavant.

6 À lire que cette monographie est essentiellement constituée d'articles déjà publiés, on aurait pu craindre un manque de cohérence. Il n'en est rien. Sans être indigeste par son volume, l'ouvrage de Cristina García de Toro présente en fait une grande richesse, tant du point de vue théorique et méthodologique que de celui des perspectives de recherche. 